\title{
Application of HER2 peptide vaccines in patients with breast cancer: a systematic review and meta-analysis
}

\author{
Zicong You ${ }^{1,2+}$, Weijun Zhou ${ }^{3 \dagger}$, Junyan Weng ${ }^{1}$, Haizhan Feng ${ }^{1}$, Peiqiao Liang ${ }^{1}$, Yuhua Li ${ }^{3^{*}}$ and Fujun Shi ${ }^{1^{*}}$ (])
}

\begin{abstract}
Background: The E75 and GP2 vaccines are the few therapeutic vaccines targeting HER2 currently under clinical research for patients with breast cancer.

Methods: Databases, including the Cochrane Library, PubMed, Medline, Embase, and Web of Science, were used to retrieve clinical studies on E75 and GP2 vaccines. Retrieval time was from the beginning of database construction until May 31st, 2021.

Results: A total of 24 clinical studies were included in this analysis, including 1704 patients in the vaccinated group and 1248 patients in the control group. For the E75 vaccine, there were significant differences between the vaccinated group and the control group in the delayed-type hypersensitivity reaction (SMD $=0.68595 \% \mathrm{Cl} 0.52-0.85$, $\left.P_{\text {Heterogeneity }}=0.186, P_{\text {DTH }}<0.05\right)$ and the change in CD8 ${ }^{+}$T-cell numbers $(S M D=-0.864,95 \% \mathrm{Cl}-1.02$ to -0.709 ,

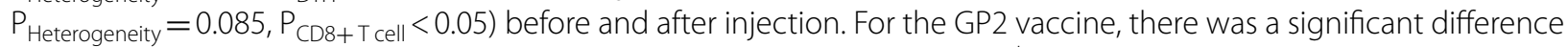
between the vaccinated group and the control group in the change in $\mathrm{CD}^{+} \mathrm{T}$-cell numbers $(\mathrm{SMD}=-0.584,95 \% \mathrm{Cl}$ -0.803 to $\left.-0.294, P_{\text {Heterogeneity }}=0.397, P_{C D 8}+T_{\text {cell }}<0.05\right)$ before and after injection. In addition, the clinical outcomes, including recurrence rate $\left(\mathrm{RR}=0.568,95 \% \mathrm{Cl} 0.444-0.727, \mathrm{P}_{\text {Heterogeneity }}=0.955, \mathrm{P}_{\text {Recurrence }}<0.05\right)$ and disease-free survival rate $\left(R R=1.149,95 \% \mathrm{Cl} 1.050-1.256, \mathrm{P}_{\text {Heterogeneity }}=0.003, \mathrm{P}_{\mathrm{DFS}}<0.05\right)$, of the E75-vaccinated group were different from those of the control group. However, we found that the overall survival rate with the $E 75$ vaccine $(R R=1.032$, $\left.95 \% \mathrm{Cl} 0.998-1.067, \mathrm{P}_{\text {Heterogeneity }}=0.476, \mathrm{P}_{\mathrm{OS}}>0.05\right)$ was not different between the two groups. Local and systemic toxicity assessments of the two vaccines showed minimal side effects.
\end{abstract}

Conclusions: The E75 vaccine was effective and safe in patients with breast cancer. The GP2 vaccine could elicit a strong immune response, but more trials are needed to confirm its clinical efficacy.

Keywords: HER2, Breast cancer, Vaccine, Systematic review, Meta-analysis

*Correspondence: liyuhua2011gz@163.com; drshifujun@163.com

${ }^{\dagger}$ Zicong You and Weijun Zhou contributed equally

1 Department of Breast Surgery, Zhujiang Hospital, Southern Medical University, No. 253, Industrial Avenue, Haizhu District, Guangzhou 510282,

China

${ }^{3}$ Department of Hematology, Zhujiang Hospital, Southern Medical University, No.253, Industrial Avenue, Haizhu District, Guangzhou 510282, China

Full list of author information is available at the end of the article

\section{Introduction}

Breast cancer is a malignant tumor originating in the ductal epithelium of the breast. In the United States, the estimated number of new cases of breast cancer in 2020 was 276,480 , accounting for approximately $30.28 \%$ of all cases of primary tumors in women [1]. In recent years, great progress has been made with peptide vaccines against tumors, which may provide a potential treatment for patients with breast cancer [2]. The mechanism of peptide vaccines mainly contains original author(s) and the source, provide a link to the Creative Commons licence, and indicate if changes were made. The images or other third party material in this article are included in the article's Creative Commons licence, unless indicated otherwise in a credit line to the material. If material is not included in the article's Creative Commons licence and your intended use is not permitted by statutory regulation or exceeds the permitted use, you will need to obtain permission directly from the copyright holder. To view a copy of this licence, visit http://creativecommons.org/licenses/by/4.0/. The Creative Commons Public Domain Dedication waiver (http://creativeco mmons.org/publicdomain/zero/1.0/) applies to the data made available in this article, unless otherwise stated in a credit line to the data. 
three parts. First, antigen-presenting cells (APCs) ingest the peptide after injection. Second, $\mathrm{CD}^{+}$ T-cells recognize APCs and generate specific cytotoxic lymphocytes (CTLs). Third, CTLs specifically recognize tumor cells expressing antigen and then release perforin and cytokines to dissolve the tumor cells [3]. Human epidermal growth factor receptor-2 (HER2) is an important regulator of the growth and development of HER2-positive breast cancer cells and is mainly expressed in embryos. Only a small amount of HER2 has been detected in normal breast cells [4]. However, approximately $20-30 \%$ of patients with breast cancer overexpress HER2 [5], which make it a popular target for the design of tumor immunotherapy.

None of the therapeutic vaccines have been formally applied in breast cancer clinical treatment, but clinical trials have been actively conducted with vaccines having different mechanisms and effects [6]. Among them, vaccines targeting HER2 have been further studied in multiple trials. HER2 peptide vaccines mainly include E75 (p369-377), GP2 (p654-662), and AE37 (p776-790). E75 is p369 with KIFGSLAFL amino acid sequence. The E75 vaccine has been demonstrated to be effective and safe in several clinical studies [7, 8]. In a phase I/II trial involving 187 participants, Mittendorf EA [9] found that the disease-free survival (DFS) rate in the E75 vaccine group was different from that in the control group ( $89.7 \%$ vs. $80.2 \%)$. In addition, the GP2 peptide vaccine, known as p654 with a sequenced IISAVVGIL, was confirmed to induce patients with breast cancer to generate specific $\mathrm{CD} 8^{+} \mathrm{T}$-cells $[10$, 11]. Mittendorf EA [12] verified the clinical efficacy of the GP2 peptide vaccine in a clinical study involving 180 patients, and DFS was $88 \%$ higher than that of the control group (80\%). The AE37 peptide vaccine was obtained by adding II-key peptide (LRMK) with a length of four amino acids on the AE36 base (the sequence is GVGSPYVSRLLGICL). Compared with AE36 vaccines, the ability of the AE37 vaccine to bind to human major histocompatibility complex class II was enhanced 250 times [13]. Few clinical trials have been conducted with AE37 [14]. In a phase I trial, Holmes [15] showed that AE37 elicited a strong immune response, and its delayed-type hypersensitivity reaction (DTH) increased to $56 \mathrm{~mm}^{2}$ after injection. The above studies indicated that the HER2 vaccine has fairly broad prospects for the treatment of breast cancer. However, there have been few systematic evaluations and meta-analyses on the efficacy of HER2 vaccines. Therefore, this study intended to systematically evaluate the immunogenicity and clinical efficacy of the E75 and GP2 vaccines.

\section{Materials and methods}

\section{Protocol and registration}

A protocol was formulated for this study, and it was registered in PROSPERO (https://www.crd.york.ac.uk/ PROSPERO/) with number CRD42020218012.

\section{Criteria for literature retrieval}

Search keywords included "breast cancer", "breast neoplasia", "Random", "Randomized Trial", "HER2", "Erbb2", and "vaccine". Retrieval time was from the beginning of database construction until May 31, 2021. The retrieval language was English. The retrieval strategy was a combination of keywords and retrieval methods to improve recall and precision. Meeting summaries, reviews, case reports, letters, and unrelated studies were manually excluded. Relevant clinical research literature was searched in the Cochrane Library, PubMed, Medline, Embase, and Web of Science databases (Fig. 1 for details). The results were retrieved separately by two independent researchers and compared. If a dispute was raised, a third researcher was asked to resolve the discrepancy.

\section{Inclusion and exclusion criteria Inclusion criteria}

Clinical research literature published in journals starting on the date when the abovementioned database was established until May 31, 2021. The subjects of the study were female patients with breast cancer diagnosed by pathology without any other type of tumor. The literature used the following evaluation methods: changes in CD8 + T-cells before and after vaccine injection, measured value of the delayed-type hypersensitivity reaction (DTH), recurrence rate of tumor patients, overall survival rate, and disease-free survival rate (DFS) of patients.

\section{Exclusion criteria}

Reviews, meeting abstracts, basic studies and clinical studies unrelated to HER2 vaccine, and studies with unclear data description or poor quality. For literature reporting the same study multiple times, the latest publication was included for analysis.

\section{Clinical trial selection and data extraction}

In this study, two independent researchers simultaneously searched the relevant literature, compared and evaluated the titles and abstracts, and conducted a fulltext assessment for detailed analysis and data extraction of the studies that were suitable for inclusion criteria. 


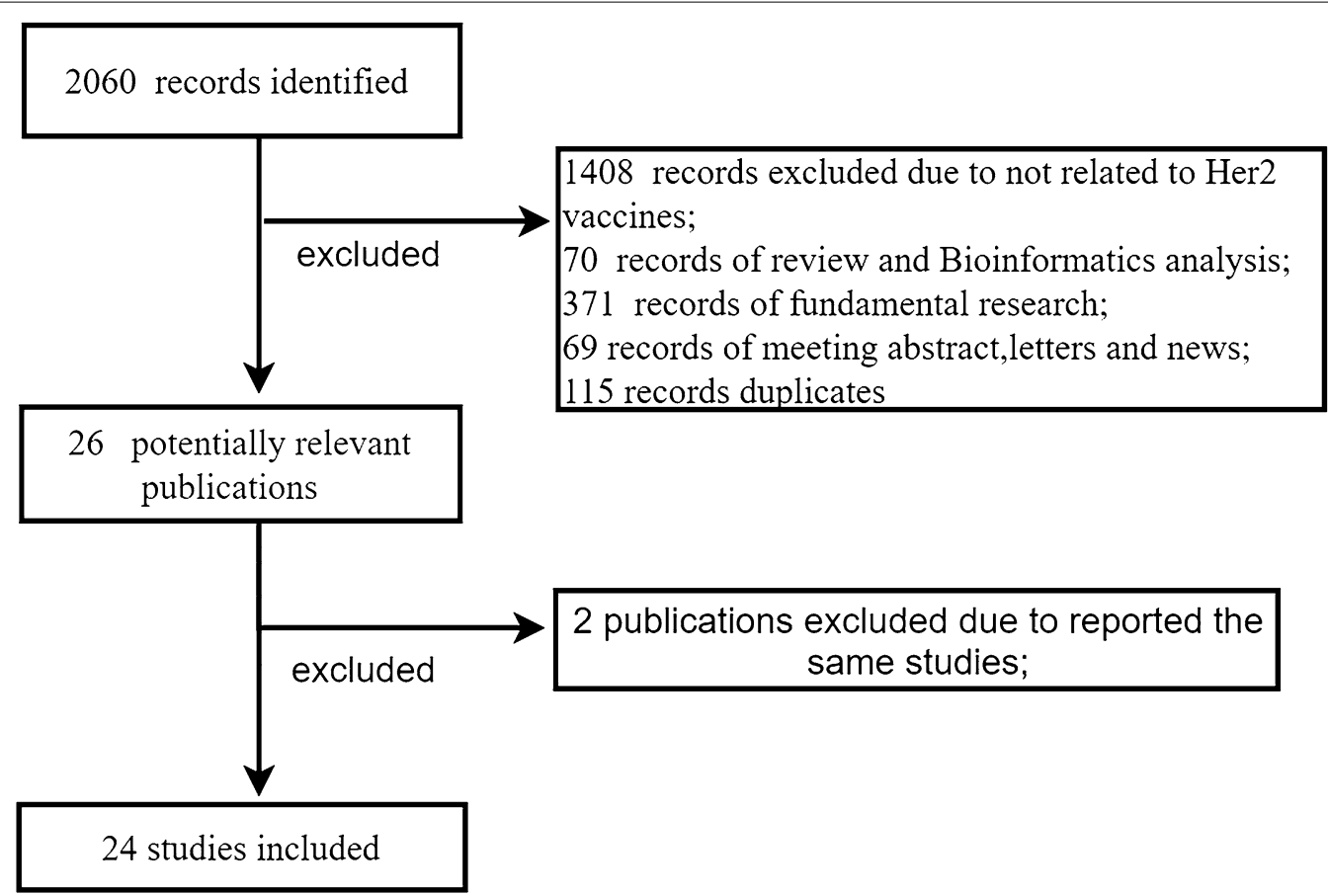

Fig. 1 Flow diagram showing the procedure used to select trials

When there were differences, the full texts were evaluated by a third researcher.

\section{Literature quality evaluation}

The quality of the included studies was assessed according to the Cochrane risk bias assessment tool [16], which contained random sequence generation (selection bias), allocation concealment (selection bias), blinding of participants and personnel (performance bias), blinding of outcome assessment (detection bias), incomplete outcome data (attrition bias), selective reporting (reporting bias), and other biases.

\section{Statistical analysis}

STATA15.1, RevMan 5.3 and Excel 2019 were used for meta-analysis of the original data obtained in the literature. The standard mean differences (SMDs) and corresponding 95\% confidence intervals (CIs) were applied to calculate the immune response of the E75 and GP2 vaccines, and relative risk (RR) and 95\% confidence interval (CI) were used to represent the results of the clinical efficacy analysis. Binary variables were analyzed using the Mantel-Haenszel method, and continuous variables were analyzed with the inverse variance method. Heterogeneity among studies was evaluated with the $X^{2}$-based $Q$-test and quantitative metric $\mathrm{I}^{2}$. Data with high heterogeneity $\left(\mathrm{P}<0.10, \mathrm{I}^{2}>50 \%\right)$ were analyzed with a random effects model. Otherwise, a fixed effects model was used for analysis with test level $=0.05$. The results of the meta-analysis were represented by forest plots, and publication bias was evaluated with Egger's and Begg's tests.

\section{Results Included studies}

A total of 24 clinical studies were included in this study, all of which were phase I/II/III clinical studies on breast cancer. There were 1704 patients in the vaccinated group and 1248 patients in the control group, including patients with positive HER2 expression, negative HER2 expression, positive axillary lymph node(s), or negative axillary lymph node(s). Altogether, 1580 patients in the vaccinated group and 1156 patients in the control group were enrolled in 21 clinical trials of E75. Three clinical trials of the GP2 vaccine, including 124 patients in the vaccinated group and 91 patients in the control group, were enrolled (Table 1 for details). All enrolled patients had received standard therapy. Patients in the GP2-vaccinated group were injected with the GP2 vaccine + granulocyte-macrophage colony stimulating factor (GM-CSF), while patients in the control group were injected with GM-CSF only. Patients in the E75-vaccinated group were injected with the E75 vaccine + GM-CSF, and patients in the control group were injected with GM-CSF. The mean age of the patients was $41.8 \mathrm{yrs}$. 


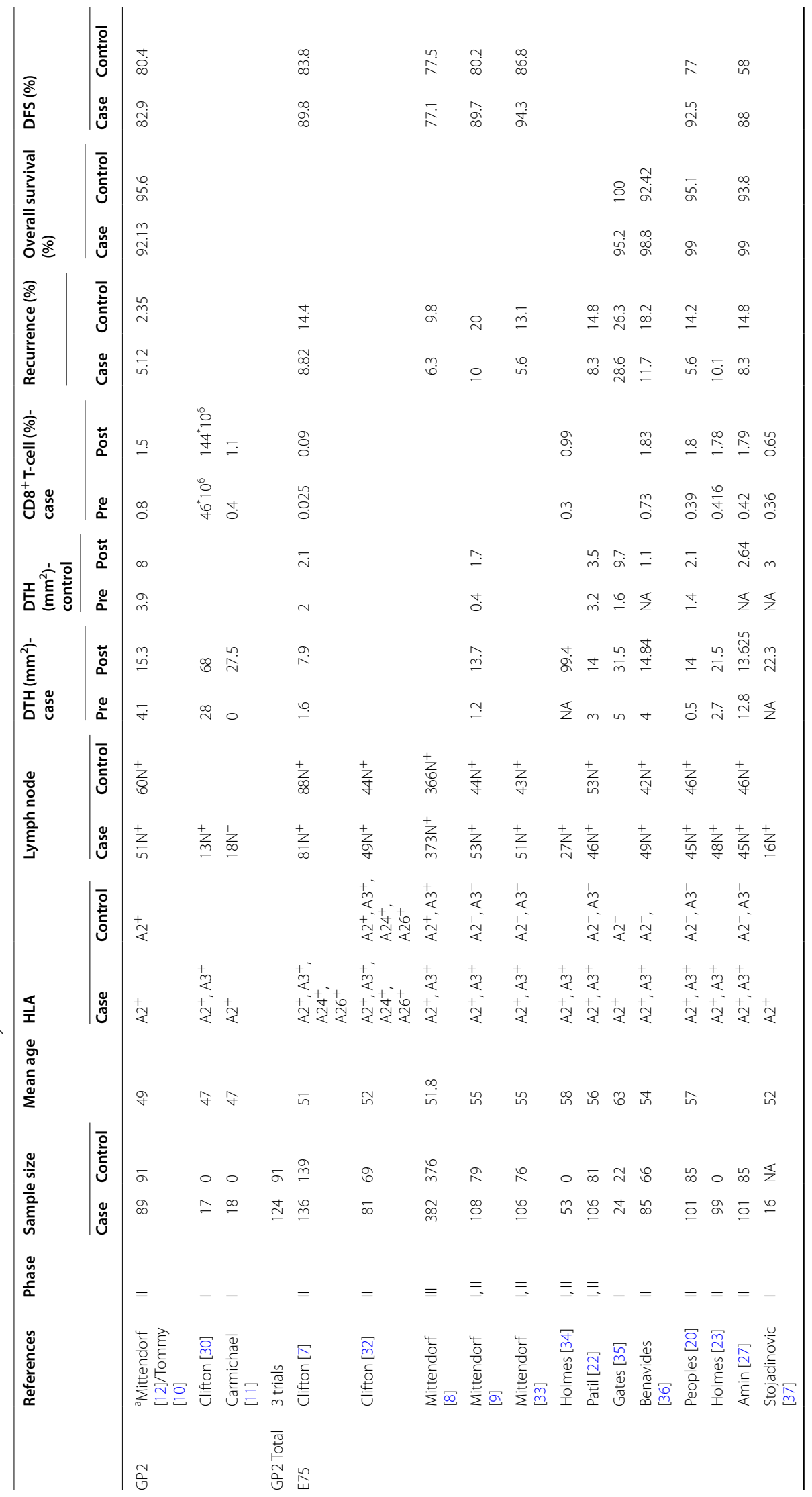




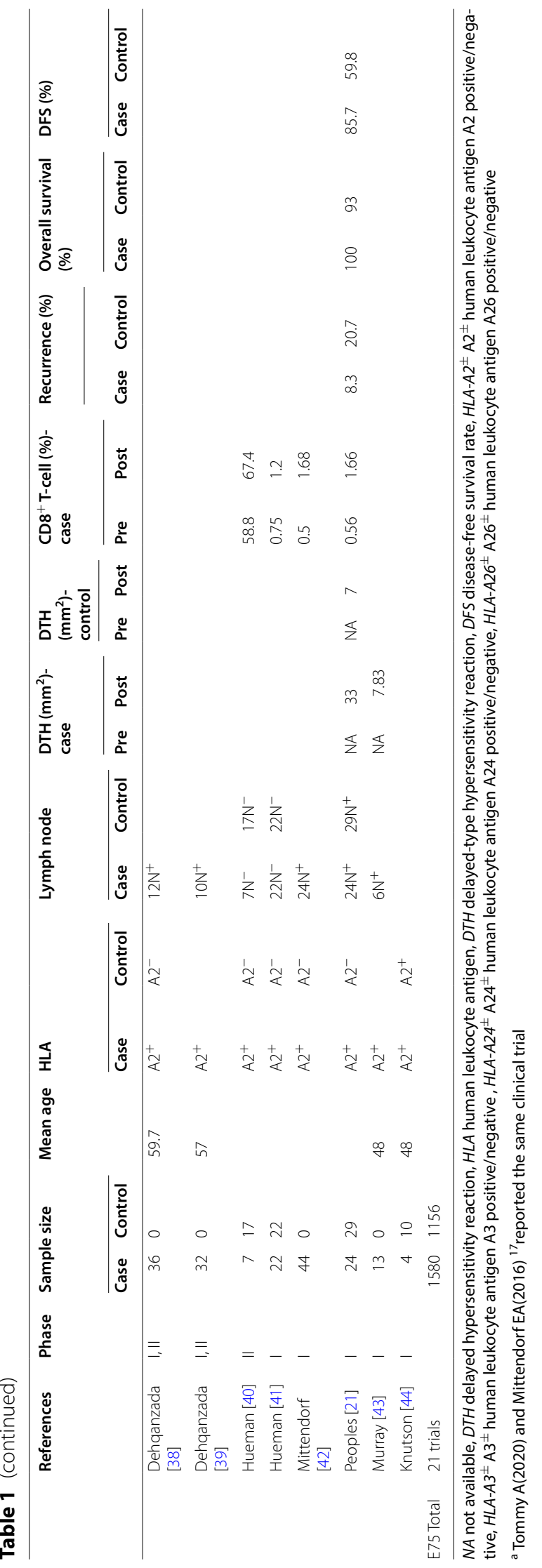




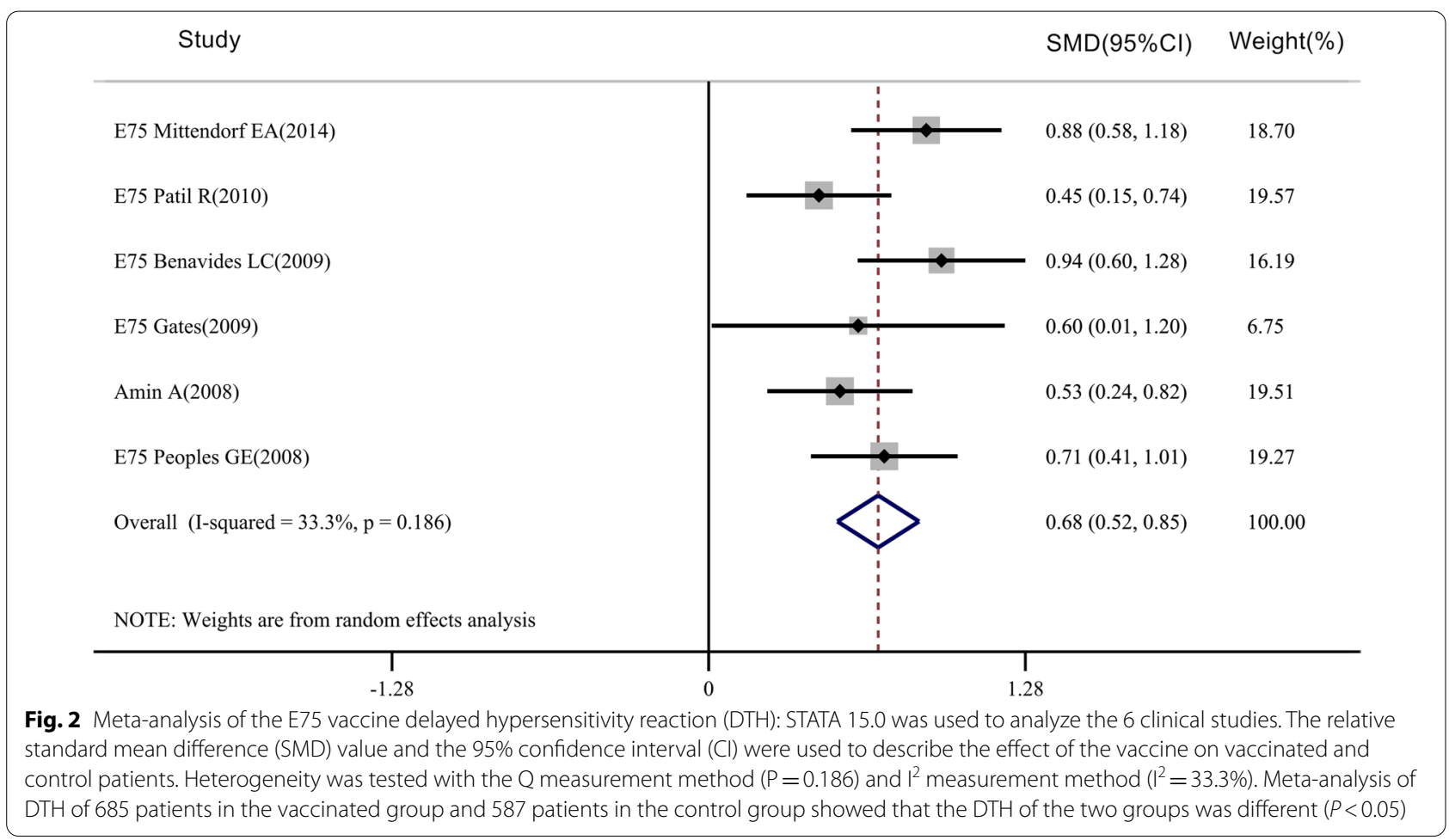

\section{Immune responses}

The immune responses of HER2 vaccines are mainly evaluated by delayed-type hypersensitivity reaction (DTH) and changes in $\mathrm{CD}^{+} \mathrm{T}$-cell numbers $[17,18]$. A metaanalysis was conducted on the DTH of 685 patients in the vaccinated group and 587 patients in the control group of the E75 vaccine (Fig. 2). The results showed that the DTH of the E75 vaccine in the vaccinated group was higher than that in the control group $(\mathrm{SMD}=0.68595 \% \mathrm{CI} 0.52-$ $\left.0.85, \mathrm{P}_{\text {Heterogeneity }}=0.186, \mathrm{P}_{\mathrm{DTH}}<0.05\right)$. Changes in $\mathrm{CD}^{+}$ $\mathrm{T}$-cell numbers before and after injection can reflect the strength of the immune response to therapeutic vaccines [19]. A comparison of the E75 vaccine in 651 patients in the vaccinated group before and after the injection of the vaccine was performed (Fig. 3), and there was a significant difference in the change in $\mathrm{CD}^{+} \mathrm{T}$-cell numbers before and after injection $(\mathrm{SMD}=-0.864,95 \% \mathrm{CI}-1.02$ to $\left.-0.709, \mathrm{P}_{\text {Heterogeneity }}=0.085, \mathrm{P}_{\mathrm{CD} 8+\mathrm{T} \text { cell }}<0.05\right)$. In addition, the number of $\mathrm{CD}^{+} \mathrm{T}$-cells in patients receiving the GP2 vaccine also showed a significant difference before and after injection. (SMD $=-0.584,95 \% \mathrm{CI}$ -0.803 to $-0.294, \mathrm{P}_{\text {Heterogeneity }}=0.397, \mathrm{P}_{\mathrm{CD} 8}+\mathrm{T}$ cell $\left.<0.05\right)$ (Fig. 4). The results showed that E75 and GP2 vaccines both had strong immunogenicity.

\section{Clinical outcomes}

The meta-analysis of the E75 vaccine recurrence rate included 10 clinical trials, with follow-up times ranging from 17 to 60 months, including 1517 patients in the vaccinated group and 1217 patients in the control group (Fig. 5). The results showed that the recurrence rate in the E75-vaccinated group was different from that of the control group $(\mathrm{RR}=0.568,95 \% \mathrm{CI} 0.444-0.727$, $\left.\mathrm{P}_{\text {Heterogeneity }}=0.955, \mathrm{P}_{\text {recurrence }}<0.05\right)$.

The meta-analysis of overall survival (OS) rate included 5 clinical studies on the E75 peptide vaccine (Fig. 6), with 335 patients in the vaccinated group and 287 patients in the control group. However, we found that for the E75 vaccine $(R R=1.032,95 \%$ CI $0.998-1.067$, $\left.\mathrm{P}_{\text {Heterogeneity }}=0.476, \mathrm{P}_{\mathrm{OS}}>0.05\right)$, there was no significant difference between the two groups in terms of overall survival rate. For the DFS rate, 7 clinical trials were included in the meta-analysis of disease-free survival (DFS), including 962 patients in the vaccinated group and 852 patients in the control group (Fig. 7). There was a significant difference between the two groups for the DFS rate of the $E 75$ vaccine $(R R=1.149,95 \%$ CI $1.050-1.256$, $\left.\mathrm{P}_{\text {Heterogeneity }}=0.003, \mathrm{P}_{\mathrm{DFS}}<0.05\right)$.

\section{Side effects}

A total of 12 studies reported local and systemic toxicities of tumor vaccines (three studies for GP2 vaccines and 9 for E75 vaccines). Grade 1 local and systemic toxic reactions were the most common toxic side effects, and grade 2 toxic reactions were also found in most studies. Eight trials reported grade 3 systemic toxicity, including 


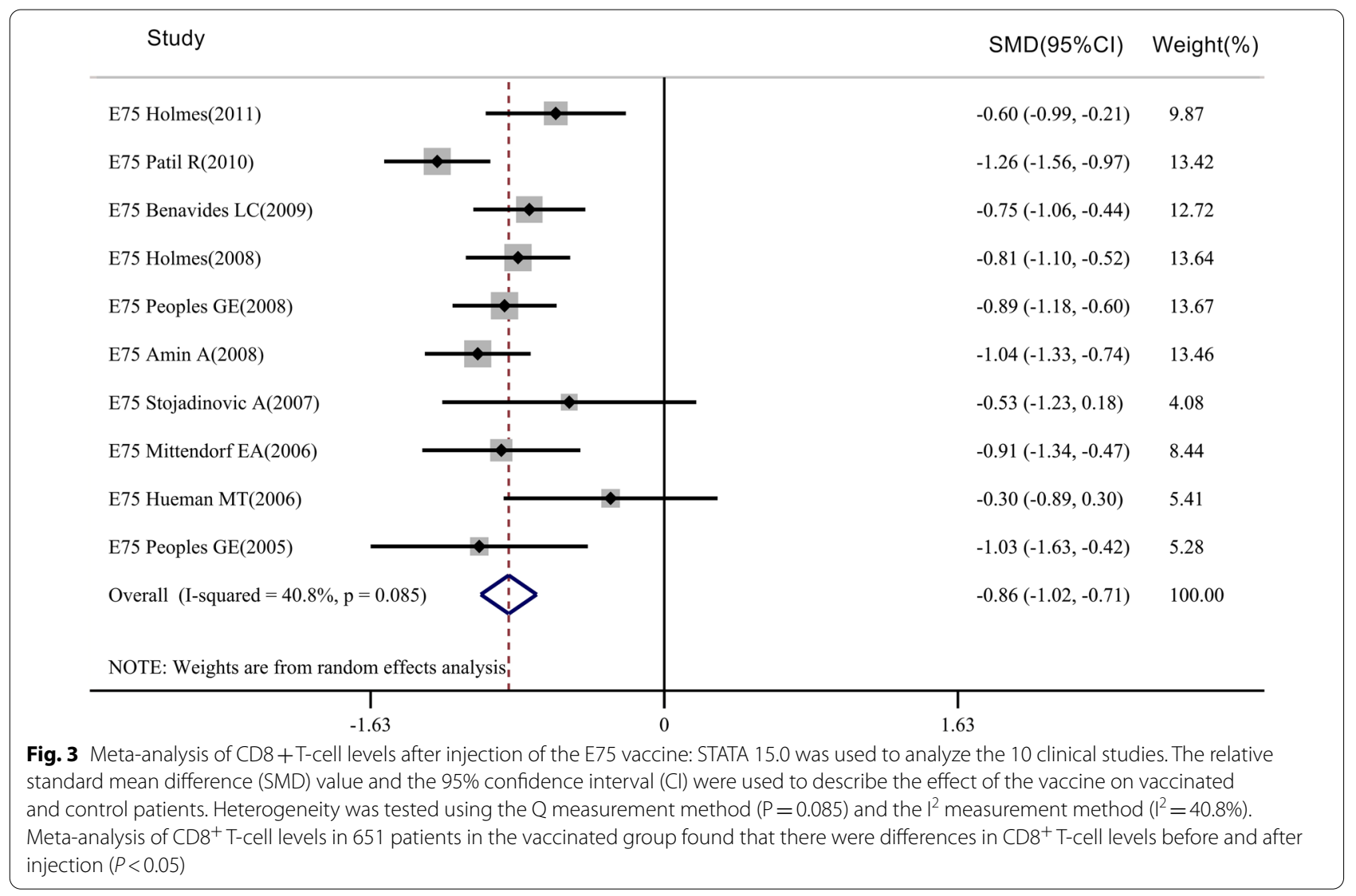

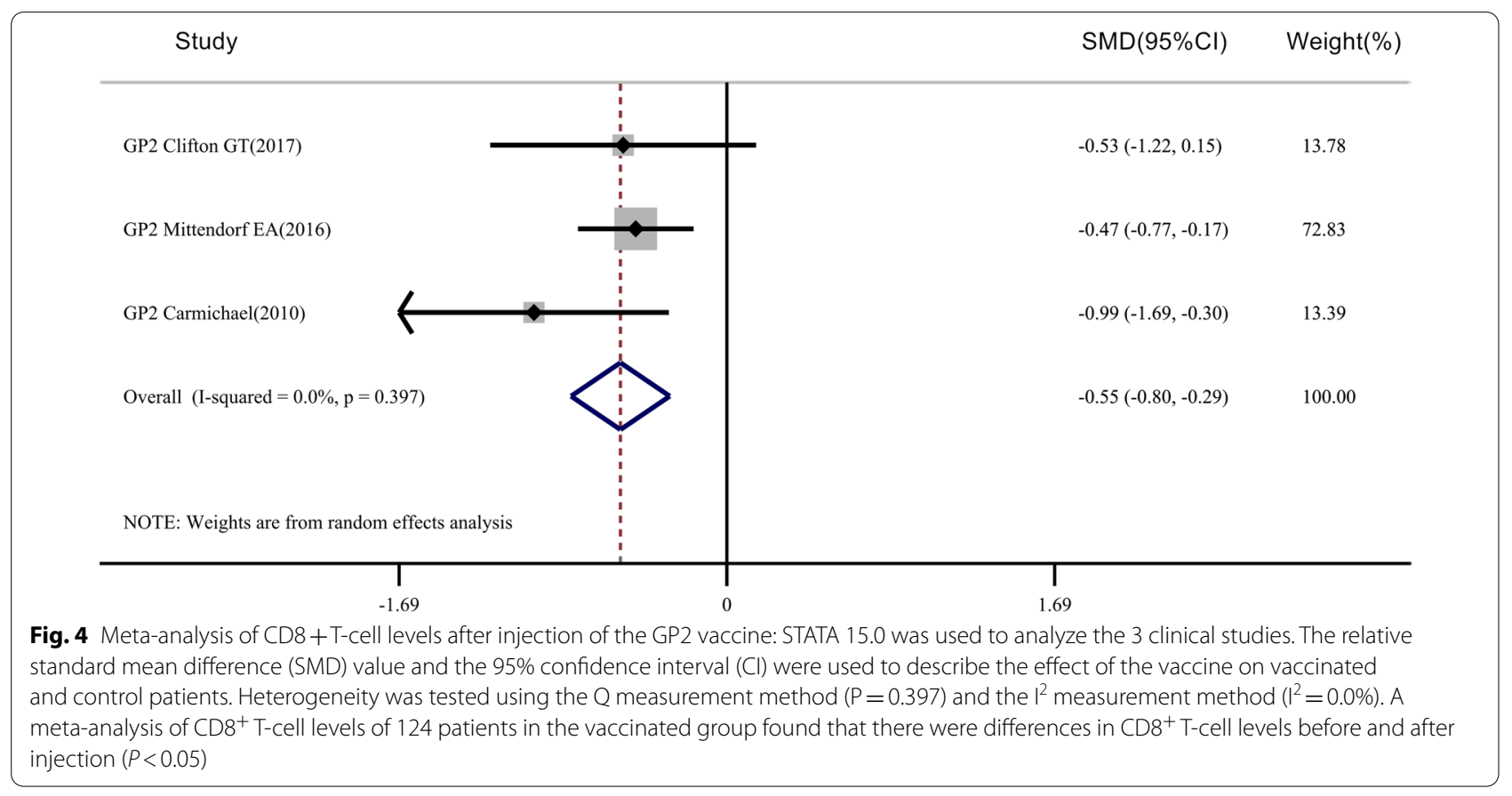




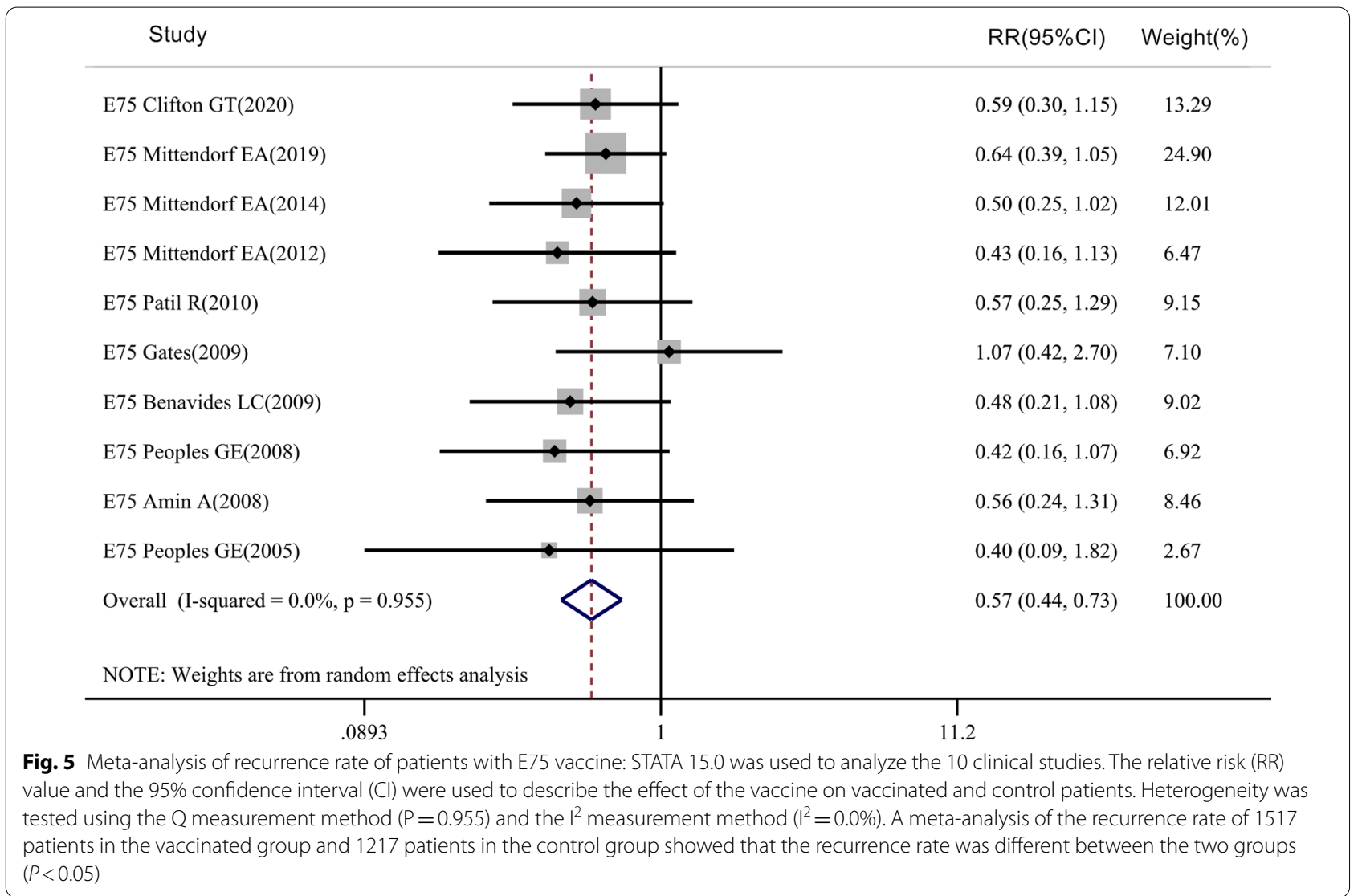

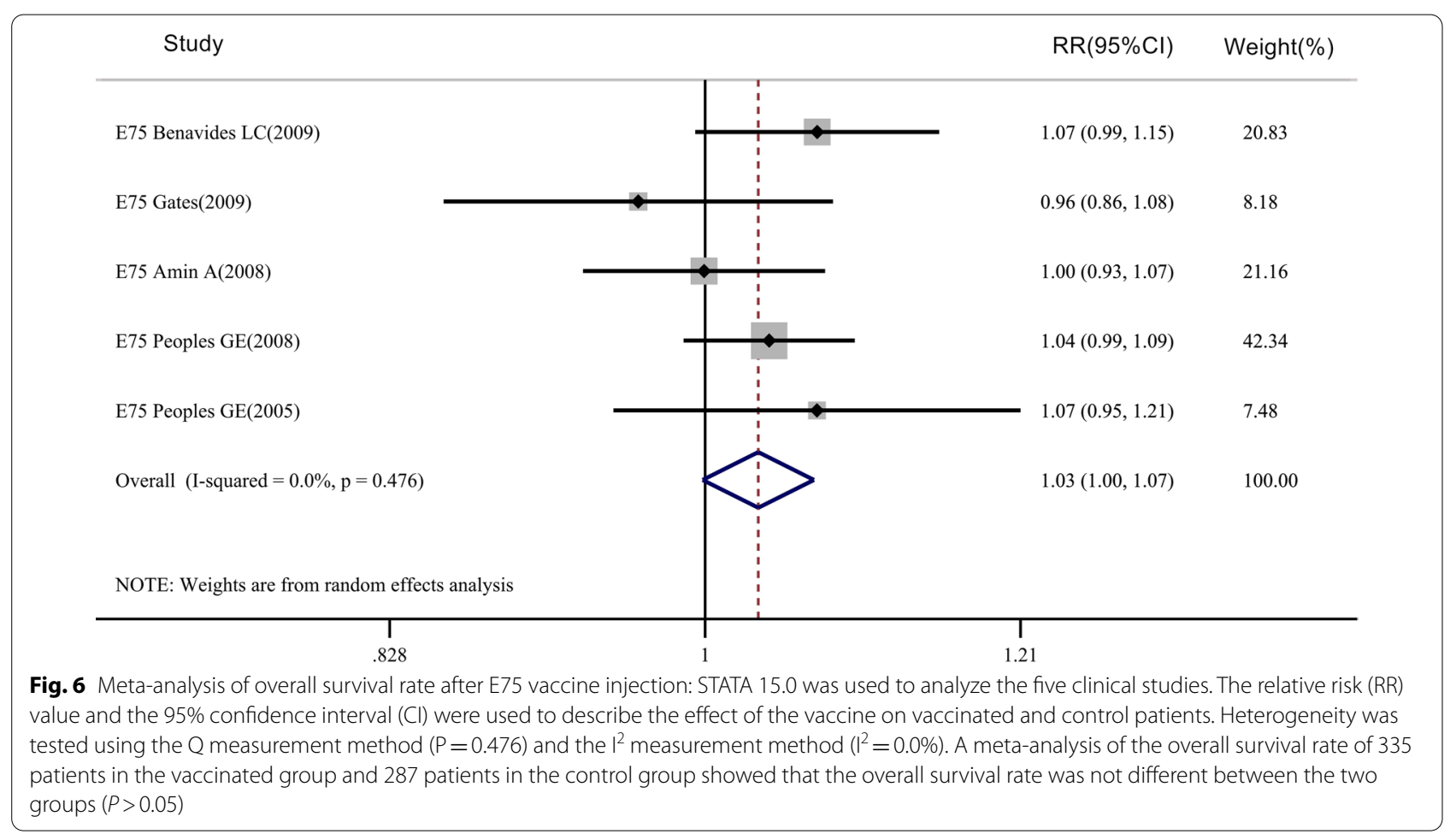




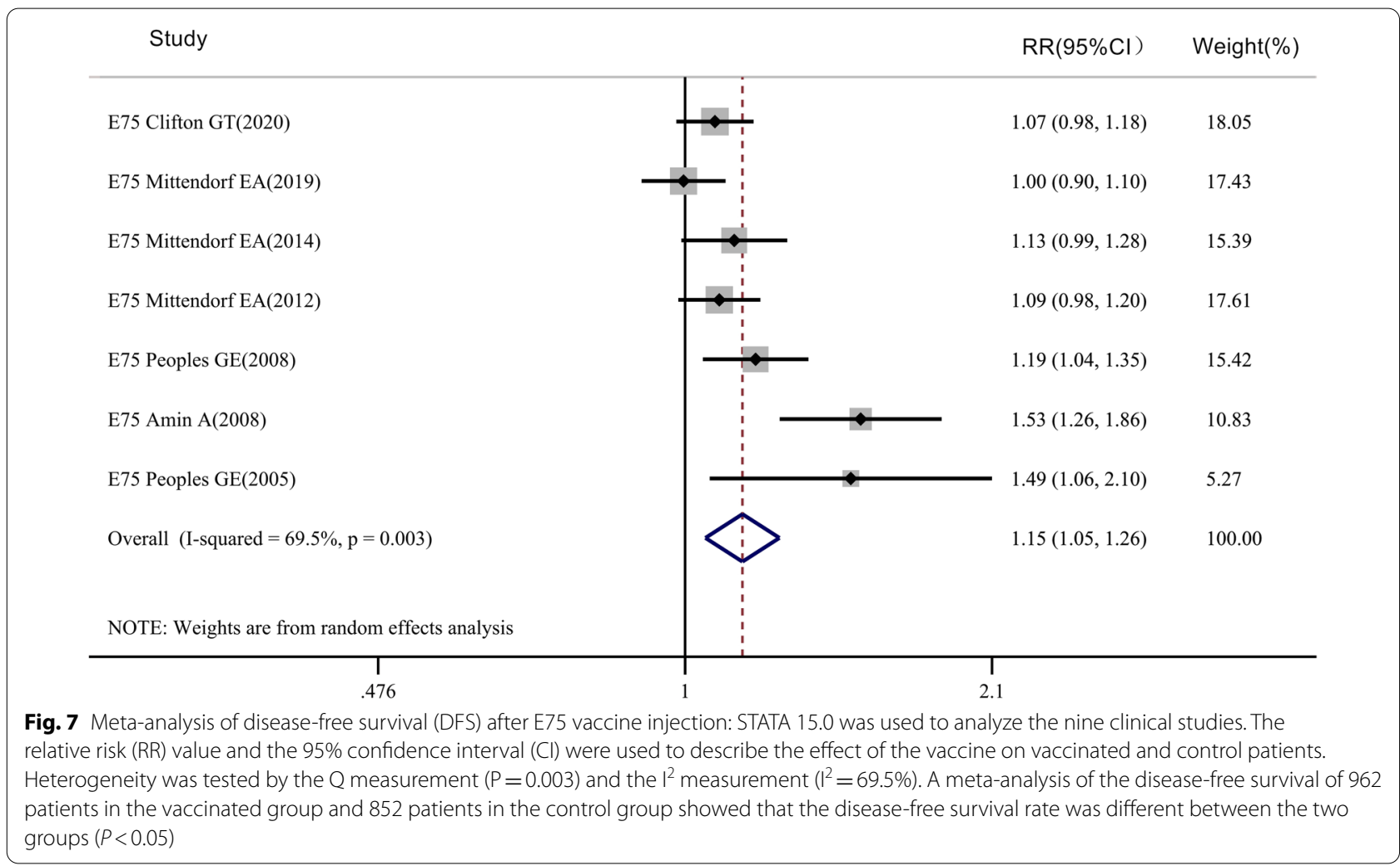

Mittendorf EA et al. [12], 1\%, Tommy et al. [10], 1\%, Peoples GE et al. [20], 2\%, Peoples GE et al. [21], 1.8\%, Patil R et al. [22], 2.3\%, Mittendorf EA et al. [8], 5.9\%, Mittendorf EA et al. [9], 1\%, and Holmes et al. [23], 1\%. One clinical trial reported grade 4 toxicity. (Mittendorf EA et al. [8], 0.3\%). The above data indicated that the GP2 and E75 vaccines had low toxicity, which provided a basis for clinical application.

\section{Study quality}

Egger's test $(t=0.99, P=0.350)$ and Begg's test $(Z=1.79$, $\mathrm{P}=0.074$ ) indicated that no publication bias existed in the studies included. The combined results of DTH $\left(\mathrm{I}^{2}=33.3 \%, \mathrm{P}=0.186\right)$ and change in $\mathrm{CD}^{+} \mathrm{T}$-cell number $\left(\mathrm{I}^{2}=40.8 \%, \mathrm{P}=0.085\right)$ in the $\mathrm{E} 75$ vaccine had mild heterogeneity. The combined result of DFS rate in the E75 vaccine had moderate heterogeneity $\left(\mathrm{I}^{2}=69.5 \%\right.$, $\mathrm{P}=0.003)$.

\section{Discussion}

With the wide application of targeted therapy, the problem of drug resistance has become increasingly significant [24]. Investigation and clinical application of the HER-2 vaccine can provide a new direction of treatment for patients with breast cancer. The efficacy of vaccines was evaluated by immunogenicity and clinical outcome [8].
Delayed hypersensitivity reaction refers to the redness, sclerosis, and even blisters and necrosis at the injection site 48-72 $\mathrm{h}$ after injection. This was a local hypersensitive inflammatory response caused by the binding of sensitized T-lymphocytes to antibodies [25]. This was one of the most common indices to evaluate the immunogenicity of therapeutic vaccines. Multiple clinical trials have shown that the E75 vaccine can elicit an immune response in the treatment of breast cancer [26]. In a phase II clinical trial of the E75 vaccine containing 196 patients, Amin A [27] found that the redness of the vaccinated nonrecurrent group increased to $13.5 \pm 1.5 \mathrm{~mm}^{2}$, and another study found that DTH responses $\geq 10 \mathrm{~mm}^{2}$ were related to vaccine immunity [28]. However, in another phase II clinical trial involving 275 patients with breast cancer, Clifton GT [7] found that the mean DTH response in the E75 vaccine group was $7.9 \mathrm{~mm}^{2}$. To confirm its immunogenicity, we conducted a metaanalysis on DTH of the E75 vaccine and found that there were differences between the vaccinated group and the control group in DTH (SMD $=0.685$ 95\% CI 0.52-0.85, $\left.\mathrm{P}_{\text {Heterogeneity }}=0.186, \mathrm{P}_{\mathrm{DTH}}<0.05\right)$, which showed that the E75 vaccine could elicit a DTH response in six included studies. Changes in $\mathrm{CD}^{+}$T-cells reflect the strength of the immune response after vaccination [29]. In this study, we found that $\mathrm{CD}^{+} \mathrm{T}$-cell numbers were different before 
and after injection in ten studies (SMD $=-0.864,95 \% \mathrm{CI}$ -1.02 to $\left.-0.709, \mathrm{P}_{\text {Heterogeneity }}=0.085, \mathrm{P}_{\mathrm{CD} 8+\mathrm{T} \text { cell }}<0.05\right)$.

Regarding clinical outcomes, in a phase I/II clinical trial of 187 patients with breast cancer, Patil R [22] found that the E75 vaccine group was associated with an $8.3 \%$ recurrence rate compared with $14.8 \%$ in the control group, and the overall survival rate was $99 \%$ in the vaccinated group compared with $93.8 \%$ in the control group. However, its long-term efficacy in patients with breast cancer is still controversial. Mittendorf EA [8], in a multicenter clinical trial including 758 participants, concluded that there was no significant difference in DFS rate between a E75 vaccinated group and a control group. In view of this, a meta-analysis of clinical outcomes including recurrence rate, OS rate, and DFS rate of the E75 vaccine was conducted, and it found that the E75 vaccine not only differed between vaccinated group and control group in recurrence rate in ten studies $(R R=0.568,95 \%$ CI $\left.0.444-0.727, \quad P_{\text {Heterogeneity }}=0.955, \quad P_{\text {recurrence }}<0.05\right)$ but also in DFS rate in seven studies $(\mathrm{RR}=1.149,95 \%$ CI $1.050-1.256, \mathrm{P}_{\text {Heterogeneity }}=0.003, \mathrm{P}_{\mathrm{DFS}}<0.05$ ). However, the overall survival rate was not different between the two groups. ( $R R=1.032,95 \%$ CI 0.998-1.067, $\left.\mathrm{P}_{\text {Heterogeneity }}=0.476, \mathrm{P}_{\mathrm{OS}}>0.05\right)$. The results above confirmed the immunogenicity and clinical efficacy of the E75 vaccine in patients with breast cancer.

In terms of the GP2 vaccine, Clifton GT [30] found that it could elicit an immune response in patients with breast cancer in a phase I clinical trial, thus demonstrating its immunogenicity. However, studies show that the ability of the GP2 vaccine to induce the generation of specific antitumor cells was relatively weaker than that of the E75 and AE37 vaccines [12]. Therefore, we conducted a metaanalysis of the GP2 vaccine and found that the GP2 vaccine could elicit a strong immune response resulting in a change in $\mathrm{CD}^{+} \mathrm{T}$-cell numbers in three studies before and after injection (SMD $=-0.584,95 \% \mathrm{CI}-0.803$ to $-0.294, \mathrm{P}_{\text {Heterogeneity }}=0.397, \mathrm{P}_{\mathrm{CD} 8}+\mathrm{T}$ cell $\left.<0.05\right)$. Because of the limited number of clinical trials on the GP2 vaccine, data for further analysis of the clinical efficacy of the GP2 vaccine are insufficient. Mittendorf EA [12] verified the clinical efficacy of the GP2 peptide vaccine in a clinical trial involving 180 patients, and DFS was $88 \%$ higher than that of the control group (80\%). However, with longterm follow-up, Tommy A [10] refuted the conclusion that the DFS of the vaccinated and control groups was not significantly different. The clinical efficacy of the GP2 vaccine needs to be confirmed with more clinical trials.

According to the Common Terminology Criteria for Adverse Events (Version 5.0), Grade 3 indicates a severe or medically significant disabling event, limiting self-care, but not immediately life-threatening, with hospitalization or prolongation of hospitalization indicated; Grade
4 indicates life-threatening consequences and urgent intervention indicated [31]. We found that the study that reported the most participants of grade 3 was the one by Mittendorf EA et al. [8], with 5.9\%, and the only study that reported grade 4 was the one by Mittendorf EA et al. [8], with $0.3 \%$. The results showed that the E75 and GP2 vaccines had low local and systemic toxicities and were safe for patients with breast cancer.

In the mechanism of action of peptide vaccines, the binding of APCs and T-helper cells requires mutual recognition of antigens and human leukocyte antigen (HLA) molecules [3]. The type of human HLA must be considered in the application of peptide vaccines. The E75 and GP2 vaccines were only available to people with HLA$\mathrm{A}^{+}{ }^{+}$and HLA-A $3^{+}$. This was one of the limitations of the widespread application of peptide vaccines. Pre-existing immunity to the vaccine referred to peptide-specific dimer levels $\geq 0.3 \%$ before vaccination. According to Carmichael [11], pre-existing immunity decreases the ability of patients to generate specific CTLs after vaccination, which may reduce the efficacy of vaccines. In addition, drug resistance, toxicity and high costs are factors that need to be considered.

The limitations of this study were related to the quantity and quality of studies included about GP2 vaccines. The conclusion of the GP2 vaccine might be less accurate for the relatively small number of studies included. The effect of GP2 vaccines on long-term treatment needs to be evaluated and analyzed with more clinical trials. Although the disease-free survival rate with the E75 vaccine had moderate heterogeneity, these studies are supportive of the efficacy of the E75 vaccine. The heterogeneity among studies possibly comes from the stage of breast cancer, age, dose of the vaccine, clinical nodal status, and pre-existing immune status to the vaccine.

\section{Conclusion}

Our meta-analysis results demonstrated that the E75 vaccine was effective and safe in patients with breast cancer. The GP2 vaccine could elicit a strong immune response, but its clinical efficacy needs to be confirmed with more clinical trials.

\section{Acknowledgements \\ We thank the Library of the Southern Medical University for providing the full-text manuscripts.}

\section{Authors' contributions}

ZY contributed with data acquisition, data analysis and interpretation, drafting of the manuscript, and statistical analysis; WZ and JW contributed with data acquisition, analysis, and interpretation, and statistical analysis; HF and PL contributed with acquisition of data; YL contributed with improvement of the study concept and study supervision and revision of the manuscript; FS contributed to the study concept and design and study supervision, obtained funding, and critically revised the manuscript for important intellectual content. All authors read and approved the final manuscript. 


\section{Funding}

This study was funded by the CSCO-Roche Oncology Research Fund (Y-Roche2019/2-0086)

\section{Availability of data and materials}

All data analyzed in the study are available in the published manuscripts.

\section{Declarations}

Ethics approval and consent to participate

This study is a systematic review, and it does not require approval of an ethics committee.

\section{Consent for publication}

Not applicable.

\section{Competing interests}

The authors declare no competing interests.

\section{Author details}

${ }^{1}$ Department of Breast Surgery, Zhujiang Hospital, Southern Medical University, No. 253, Industrial Avenue, Haizhu District, Guangzhou 510282, China. ${ }^{2}$ Department of Thoracic and Breast Surgery, Foshan Hospital of Traditional Chinese Medicine, Guangzhou University of Chinese Medicine, No.6,Qinren Road,Chancheng District, Foshan 528000, China. ${ }^{3}$ Department of Hematology, Zhujiang Hospital, Southern Medical University, No.253, Industrial Avenue, Haizhu District, Guangzhou 510282, China.

Received: 9 April 2021 Accepted: 30 August 2021 Published online: 15 September 2021

\section{References}

1. Siegel RL, Miller KD, Jemal A. Cancer statistics, 2020. CA. 2020;70(1):7-30

2. Sorolla A, Sorolla MA, Wang E, Cena V. Peptides, proteins and nanotechnology: a promising synergy for breast cancer targeting and treatment. Expert Opin Drug Deliv. 2020;17(11):1597-613.

3. Cui N, Shi J, Yang C. HER2-based immunotherapy for breast cancer. Cancer Biother Radio. 2018;33(5):169-75.

4. Oh DY, Bang YJ. HER2-targeted therapies - a role beyond breast cancer. Nat Rev Clin Oncol. 2020;17(1):33-48.

5. Slamon DJ, Godolphin W, Jones LA, Holt JA, Wong SG, Keith DE, Levin WJ, Stuart SG, Udove J, Ullrich A, et al. Studies of the HER-2/ neu proto-oncogene in human breast and ovarian cancer. Science. 1989;244(4905):707-12.

6. Costa R, Czerniecki BJ. Clinical development of immunotherapies for HER2(+) breast cancer: a review of HER2-directed monoclonal antibodies and beyond. NPJ Breast Cancer. 2020;6:10.

7. Clifton GT, Hale D, Vreeland TJ, Hickerson AT, Litton JK, Alatrash G, Murthy RK, Qiao N, Philips AV, Lukas JJ, et al. Results of a randomized phase IIb trial of nelipepimut-S + trastuzumab versus trastuzumab to prevent recurrences in patients with high-risk HER2 low-expressing breast cancer. Clin Cancer Res. 2020;26(11):2515-23.

8. Mittendorf EA, Lu B, Melisko M, Price Hiller J, Bondarenko I, Brunt AM, Sergii G, Petrakova K, Peoples GE. Efficacy and safety analysis of nelipepimut$S$ vaccine to prevent breast cancer recurrence: a randomized, multicenter, phase III clinical trial. Clin Cancer Res. 2019;25(14):4248-54.

9. Mittendorf EA, Clifton GT, Holmes JP, Schneble E, van Echo D, Ponniah S, Peoples GE. Final report of the phase I/II clinical trial of the E75 (nelipepimut-S) vaccine with booster inoculations to prevent disease recurrence in high-risk breast cancer patients. Ann Oncol. 2014;25(9):1735-42.

10. Brown TA, Mittendorf EA, Hale DF, Myers JW, Peace KM, Jackson DO, Greene JM, Vreeland TJ, Clifton GT, Ardavanis A, et al. Prospective, randomized, single-blinded, multi-center phase II trial of two HER2 peptide vaccines, GP2 and AE37, in breast cancer patients to prevent recurrence. Breast Cancer Res Treat. 2020;181(2):391-401.

11. Carmichael MG, Benavides LC, Holmes JP, Gates JD, Mittendorf EA, Ponniah S, Peoples GE. Results of the first phase 1 clinical trial of the HER-2/ neu peptide (GP2) vaccine in disease-free breast cancer patients. Cancer. 2010;116(2):292-301.

12. Mittendorf EA, Ardavanis A, Litton JK, Shumway NM, Hale DF, Murray JL, Perez SA, Ponniah S, Baxevanis CN, Papamichail M, et al. Primary analysis of a prospective, randomized, single-blinded phase II trial evaluating the HER2 peptide GP2 vaccine in breast cancer patients to prevent recurrence. Oncotarget. 2016;7(40):66192-201.

13. Mittendorf EA, Ardavanis A, Symanowski J, Murray JL, Shumway NM, Litton JK, Hale DF, Perez SA, Anastasopoulou EA, Pistamaltzian NF, et al. Primary analysis of a prospective, randomized, single-blinded phase II trial evaluating the HER2 peptide AE37 vaccine in breast cancer patients to prevent recurrence. Ann Oncol. 2016;27(7):1241-8.

14. McCarthy PM, Clifton GT, Vreeland TJ, Adams AM, O'Shea AE, Peoples GE. AE37: a HER2-targeted vaccine for the prevention of breast cancer recurrence. Expert Opin Investig Drugs. 2021;30(1):5-11.

15. Holmes JP, Benavides LC, Gates JD, Carmichael MG, Hueman MT, Mittendorf EA, Murray JL, Amin A, Craig D, von Hofe E, et al. Results of the first phase I clinical trial of the novel II-key hybrid preventive HER-2/neu peptide (AE37) vaccine. J Clin Oncol. 2008;26(20):3426-33.

16. Higgins JP, Altman DG, Gotzsche PC, Juni P, Moher D, Oxman AD, Savovic J, Schulz KF, Weeks L, Sterne JA. The Cochrane collaboration's tool for assessing risk of bias in randomised trials. BMJ. 2011;343: d5928.

17. Ross JS, Slodkowska EA, Symmans WF, Pusztai L, Ravdin PM, Hortobagyi GN. The HER-2 receptor and breast cancer: ten years of targeted antiHER-2 therapy and personalized medicine. Oncologist. 2009;14(4):320-68.

18. Solinas C, Aiello M, Migliori E, Willard-Gallo K, Emens LA. Breast cancer vaccines: heeding the lessons of the past to guide a path forward. Cancer Treat Rev. 2020;84: 101947.

19. Arab A, Yazdian-Robati R, Behravan J. HER2-positive breast cancer immunotherapy: a focus on vaccine development. Arch Immunol Ther Exp. 2020:68(1):2.

20. Peoples GE, Holmes JP, Hueman MT, Mittendorf EA, Amin A, Khoo S, Dehqanzada ZA, Gurney JM, Woll MM, Ryan GB, et al. Combined clinical trial results of a HER2/neu (E75) vaccine for the prevention of recurrence in high-risk breast cancer patients: U.S. Military Cancer Institute Clinical Trials Group Study I-01 and I-02. Clin Cancer Res. 2008;14(3):797-803.

21. Peoples GE, Gurney JM, Hueman MT, Woll MM, Ryan GB, Storrer CE, Fisher C, Shriver CD, loannides CG, Ponniah S. Clinical trial results of a HER2/neu (E75) vaccine to prevent recurrence in high-risk breast cancer patients. J Clin Oncol. 2005;23(30):7536-45.

22. Patil R, Clifton GT, Holmes JP, Amin A, Carmichael MG, Gates JD, Benavides LH, Hueman MT, Ponniah S, Peoples GE. Clinical and immunologic responses of HLA-A3+ breast cancer patients vaccinated with the HER2/ neu-derived peptide vaccine, E75, in a phase I/II clinical trial. J Am Coll Surgeons. 2010;210(2):140-7.

23. Holmes JP, Gates JD, Benavides LC, Hueman MT, Carmichael MG, Patil R, Craig D, Mittendorf EA, Stojadinovic A, Ponniah S, et al. Optimal dose and schedule of an HER-2/neu (E75) peptide vaccine to prevent breast cancer recurrence. Cancer. 2008;113(7):1666-75.

24. Greenwalt I, Zaza N, Das S, Li BD. Precision medicine and targeted therapies in breast cancer. Surg Oncol Clin N Am. 2020;29(1):51-62.

25. Ariza A, Torres MJ, Moreno-Aguilar C, Fernandez-Santamaria R, Fernandez TD. Early biomarkers for severe drug hypersensitivity reactions. Curr Pharm Des. 2019;25(36):3829-39.

26. Pallerla S, Abdul A, Comeau J, Jois S. Cancer vaccines, treatment of the future: with emphasis on HER2-positive breast cancer. Int J Mol Sci. 2021. https://doi.org/10.3390/ijms22020779.

27. Amin A, Benavides LC, Holmes JP, Gates JD, Carmichael MG, Hueman MT, Mittendorf EA, Storrer CE, Jama YH, Craig D, et al. Assessment of immunologic response and recurrence patterns among patients with clinical recurrence after vaccination with a preventive HER2/neu peptide vaccine: from US Military Cancer Institute Clinical Trials Group Study 1-01 and I-02. Cancer Immunol Immunother. 2008;57(12):1817-25.

28. Disis ML, Schiffman K, Gooley TA, McNeel DG, Rinn K, Knutson KL. Delayed-type hypersensitivity response is a predictor of peripheral blood T-cell immunity after HER-2/neu peptide immunization. Clin Cancer Res. 2000;6(4):1347-50.

29. Liu W, Tang H, Li L, Wang X, Yu Z, Li J. Peptide-based therapeutic cancer vaccine: current trends in clinical application. Cell Prolif. 2021;54(5): e13025. 
30. Clifton GT, Litton JK, Arrington K, Ponniah S, Ibrahim NK, Gall V, Alatrash G, Peoples GE, Mittendorf EA. Results of a phase Ib trial of combination immunotherapy with a CD8+ T cell eliciting vaccine and trastuzumab in breast cancer patients. Ann Surg Oncol. 2017;24(8):2161-7.

31. Freites-Martinez A, Santana N, Arias-Santiago S, Viera A. Using the common terminology criteria for adverse events (CTCAE-Version 50) to evaluate the severity of adverse events of anticancer therapies. Actas Dermosifiliogr. 2021;112(1):90-2.

32. Clifton GT, Peace KM, Holmes JP, Vreeland TJ, Hale DF, Herbert GS, Litton JK, Murthy RK, Lukas J, Peoples GE, et al. Initial safety analysis of a randomized phase II trial of nelipepimut-S + GM-CSF and trastuzumab compared to trastuzumab alone to prevent recurrence in breast cancer patients with HER2 low-expressing tumors. Clin Immunol. 2019;201:48-54

33. Mittendorf EA, Clifton GT, Holmes JP, Clive KS, Patil R, Benavides LC, Gates JD, Sears AK, Stojadinovic A, Ponniah S, et al. Clinical trial results of the HER-2/neu (E75) vaccine to prevent breast cancer recurrence in high-risk patients. Cancer. 2012;118(10):2594-602.

34. Holmes JP, Clifton GT, Patil R, Benavides LC, Gates JD, Stojadinovic A, Mittendorf EA, Ponniah S, Peoples GE. Use of booster inoculations to sustain the clinical effect of an adjuvant breast cancer vaccine. Cancer. 2011;117(3):463-71.

35. Gates JD, Carmichael MG, Benavides LC, Holmes JP, Hueman MT, Woll MM, loannides CG, Robson CH, McLeod DG, Ponniah S, et al. Longterm followup assessment of a HER2/neu peptide (E75) vaccine for prevention of recurrence in high-risk prostate cancer patients. J Am Coll Surgeons. 2009;208(2):193-201.

36. Benavides LC, Gates JD, Carmichael MG, Patel R, Holmes JP, Hueman MT, Mittendorf EA, Craig D, Stojadinovic A, Ponniah S, et al. The impact of HER2/neu expression level on response to the E75 vaccine: from U.S. Military Cancer Institute Clinical Trials Group Study 1-01 and I-02. Clin Cancer Res. 2009;15(8):2895-904.

37. Stojadinovic A, Mittendorf EA, Holmes JP, Amin A, Hueman MT, Ponniah S, Peoples GE. Quantification and phenotypic characterization of circulating tumor cells for monitoring response to a preventive HER2/neu vaccinebased immunotherapy for breast cancer: a pilot study. Ann Surg Oncol. 2007;14(12):3359-68.
38. Dehqanzada ZA, Storrer CE, Hueman MT, Foley RJ, Harris KA, Jama YH, Shriver CD, Ponniah S, Peoples GE. Assessing serum cytokine profiles in breast cancer patients receiving a HER2/neu vaccine using Luminex technology. Oncol Rep. 2007;17(3):687-94.

39. Dehqanzada ZA. Correlations between serum monocyte chemotactic protein-1 levels, clinical prognostic factors, and HER-2/neu vaccine-related immunity in breast cancer patients. Clin Cancer Res. 2006;12(2):478-86.

40. Hueman MT, Stojadinovic A, Storrer CE, Dehqanzada ZA, Gurney JM, Shriver CD, Ponniah S, Peoples GE. Analysis of naïve and memory CD4 and CD8 T cell populations in breast cancer patients receiving a HER2/ neu peptide (E75) and GM-CSF vaccine. Cancer Immunol Immunother. 2006;56(2):135-46.

41. Hueman MT, Stojadinovic A, Storrer CE, Foley RJ, Gurney JM, Shriver CD, Ponniah S, Peoples GE. Levels of circulating regulatory CD4+CD25+ $T$ cells are decreased in breast cancer patients after vaccination with a HER2/neu peptide (E75) and GM-CSF vaccine $\star$. Breast Cancer Res Treat. 2006;98(1):17-29.

42. Mittendorf EA, Gurney JM, Storrer CE, Shriver CD, Ponniah S, Peoples GE. Vaccination with a HER2/neu peptide induces intra- and inter-antigenic epitope spreading in patients with early stage breast cancer. Surgery. 2006;139(3):407-18.

43. Murray JL, Gillogly ME, Przepiorka D, Brewer H, Ibrahim NK, Booser DJ, Hortobagyi GN, Kudelka AP, Grabstein KH, Cheever MA, et al. Toxicity, immunogenicity, and induction of E75-specific tumor-lytic CTLs by HER-2 peptide E75 (369-377) combined with granulocyte macrophage colony-stimulating factor in $\mathrm{HLA}-\mathrm{A} 2+$ patients with metastatic breast and ovarian cancer. Clin Cancer Res. 2002;8(11):3407-18.

44. Knutson KL, Schiffman K, Cheever MA, Disis ML. Immunization of cancer patients with a HER-2/neu, HLA-A2 peptide, p 369-377, results in shortlived peptide-specific immunity. Clin Cancer Res. 2002;8(5):1014-8.

\section{Publisher's Note}

Springer Nature remains neutral with regard to jurisdictional claims in published maps and institutional affiliations.
Ready to submit your research? Choose BMC and benefit from:

- fast, convenient online submission

- thorough peer review by experienced researchers in your field

- rapid publication on acceptance

- support for research data, including large and complex data types

- gold Open Access which fosters wider collaboration and increased citations

- maximum visibility for your research: over 100M website views per year

At BMC, research is always in progress.

Learn more biomedcentral.com/submissions 